\title{
RECTIFICATIE
}

\section{Degressieve afschrijvingen}

In de formules op blz. 371 van het oktober-nummer zijn enkele onjuistheden geslopen.

(a) In formule $(2,1)$ behoort de factor $\frac{n+1}{2}$ te zijn $\frac{n+d}{2}$ zodat deze formule komt te luiden:

$(2,1) D_{i}=\left(n+\frac{d+1}{2}-i\right) \frac{A-R}{n \times \frac{n+d}{2}}$

(b) In formule $(2,3)$ zijn de haken om de vorm $1-\frac{i}{n+d}$ weggevallen. Deze formule dient te luiden:

$(2,3) B_{1}=\frac{A-R}{n} \times\left(1-\frac{i}{n+d}\right) \times(n-i)+R$

De lezer wordt verzocht deze correcties met de pen aan te brengen.

A. B. Frielink 